\title{
Propriedades mecânicas de argamassas com substituição da areia natural por escória de aciaria BSSF (baosteel's slag short flow)
}

\author{
Mechanical properties of mortars with \\ replacement of natural sand by steel \\ slag BSSF (baosteel's slag short flow)
}

\author{
Felipe Alves Amancio ${ }^{1}$, Douglas Alexandre Lima ${ }^{2}$, \\ Alisson Rodrigues de Oliveira Dias ${ }^{1}$, Esequiel Fernandes Teixeira Mesquita ${ }^{3}$, \\ Antônio Eduardo Bezerra Cabral ${ }^{1}$
}

\footnotetext{
${ }^{1}$ Programa de Pós-Graduação em Engenharia Civil - Estruturas e Construção Civil - PEC/UFC, Universidade Federal do Ceará, CEP: 60455-900, Fortaleza, CE, Brasil.

${ }^{2}$ Departamento de Estruturas e Construção Civil, Universidade Federal do Ceará, CEP: 60455-900, Fortaleza, CE, Brasil. ${ }^{3}$ Laboratório de Reabilitação e Durabilidade das Construções - LAREB, Universidade Federal do Ceará, Campus Russas, CEP 62900-000, Fortaleza, CE, Brasil.

e-mail: felipeaamancio@ hotmail.com,rodrigues_alisson@live.com,douglas.edif@gmail.com, eduardo.cabral@ufc.br, emesquita@ufc.br
}

\section{RESUMO}

A geração de resíduos tem se tornado uma questão preponderante para a indústria siderúrgica em virtude da grande quantidade de resíduos gerados, e que demandam maior planejamento na destinação desses subprodutos. Aliado a isto, a escassez de insumos de boa qualidade e em locais próximos aos centros consumidores tem aumentado o interesse por produtos que causem menor impacto ambiental e de custos mais reduzidos. Neste sentido, o presente trabalho teve por objetivo avaliar as propriedades mecânicas de argamassas com a substituição da areia natural por escória de aciaria Baosteel's Slag Short Flow. O trabalho experimental contou com ensaios de caracterização da escória, bem como caracterização das propriedades das argamassas no estado fresco nos traços 1:3, 1:5, 1:7 (cimento: agregado), 1:1:4, 1:1:6 e 1:1:8 (cimento: cal: agregado:), produzidos com a substituição da areia natural por escória nos teores de 0\%,20\%, $40 \%$ e $60 \%$, em volume. Pode-se constatar que as argamassas com maiores teores de escória demandaram uma maior quantidade de água para obter o espalhamento fixo de $260 \pm 5 \mathrm{~mm}$. A substituição da areia pela escória ocasiona um aumento significativo na massa especifica no estado endurecido e no módulo de elasticidade dinâmico, tanto para as argamassas de cimento Portland como para as mistas. Quanto a velocidade de propagação ultrassônica (VPU) o teor de substituição não influencia significativamente nas argamassas de cimento Portland , entretanto exerce influência significativa nas argamassas mistas. Em relação a resistência à compressão e a tração na flexão, apesar do teor de substituição de $40 \%$ apresentar os maiores valores de resistência à tração, conforme a análise de variância o teor de substituição não exerce influência significativa nestas propriedades.

Palavras-chave: Escória de aciaria BSSF, Argamassa, Resistência à compressão, VPU, Módulo de elasticidade dinâmico.

\begin{abstract}
The waste production has become a relevant issue for the steel industry due to the large amount of waste generated. This waste amount requires appropriated planning in the destination. Additionally, the shortage of good quality inputs near of the consumer centers have increased the interest in products that cause less environmental impact with lower costs. This way, the present work presents has main aim the assessment of the mechanical properties of mortars with replacement of natural sand by steel slag Baosteel's Slag Short Flow (BSSF). The experimental work comprised the characterization of the mortar properties in the fresh state in the proportions of 1:3,1:5, 1: 7 (cement; aggregate), 1:1:4, 1: 1: 6 and 1:1:8 (cement: lime: aggregate) . The replacement of natural sand by slag followed the rations of $0,20,40$ and $60 \%$ by volume. The results
\end{abstract}


showed that mortars with higher slag contents required a higher quantity of water to obtain the fixed spread of $260 \pm 5 \mathrm{~mm}$. The replacement of sand by slag causes a significant increase in the density in the hardened state and in the dynamic modulus of elasticity for both hydraulic and composite mortars. For the ultrasonic propagation velocity (UPV), the substitution content does not influence hydraulic mortars significantly. However, a significant influence on mixed mortars was observed. Regarding the compressive strength and flexural tensile strength, despite $40 \%$ of replacement presented the highest values of tensile strength, the substitution content does not have a significant influence on these properties, according to the analysis of variance.

Keywords: BSSF steel slag, Mortar, Mechanical properties, specific gravity, Dynamic elasticity modulus.

\section{INTRODUÇÃO}

O aço é um dos principais materiais utilizados na fabricação de uma variada gama de produtos, tais como celulares, componentes estruturais de edifícios, tubulações, aviões, entre outros, além de ser considerado um dos principais elementos que possibilitam a sociedade desfrutar da modernidade e comodidade oferecidas pelos bens de consumo [1]. A produção do aço em 2017 alcançou 1,689 bilhões de toneladas [2]. Em nível internacional, o Brasil ocupou a $9^{\circ}$ posição, com cerca de $2,1 \%$ da produção mundial - e o maior produtor da América Latina, obtendo 52,2\% dessa produção [3].

No processo de produção do aço são gerados resíduos, comumente denominados de coprodutos pela indústria siderúrgica, como a escória de alto forno e as escórias de aciaria. Em 2017, a geração de resíduos e coprodutos gerados pelas empresas associadas chegou a $607 \mathrm{~kg}$ para cada tonelada de aço produzida. Dentre os coprodutos das siderúrgicas, destacam-se a escória de alto forno e as escórias de aciaria, chegando a quase $70 \%$ dos coprodutos produzidos no ano de 2017 [4].

Devido as suas propriedades aglutinantes a escória de alto-forno pode ser reutilizada como adição ativa na fabricação de cimento Portland [5]. Consequentemente mais de $90 \%$ da escória de alto forno produzida nas siderúrgicas foram vendidas para cimenteiras em 2017 [4]. De modo diferente, as escórias de aciaria, contém baixa porcentagem de sílica amorfa e alto teor de óxidos de ferros e, consequentemente, apresentam baixa ou nenhuma atividade pozolânica em comparação com a de alto forno, não sendo adequada para produção de cimentos [6]. Com isto, em 2017, da pequena parte da escória de aciaria que foi vendida (36\% do total produzida), um total de $92 \%$ foi destinada a bases e sub-base de estradas e nivelamento de terrenos [4].

Diversos estudos demonstraram que a escória de aciaria é um produto inerte, ou seja, não possui atividade pozolânica, o que restringe seu uso como adições ativas no fabrico de cimento ou adições em concreto e argamassas [5,7]. Porém, esse material possui boas características físicas, como a alta resistência e durabilidade, o que demonstra um potencial para ser utilizada como agregados na indústria da construção civil [8, 9 , 10]

Na literatura é possível encontrar diversos estudos acerca da aplicação da escória de aciaria obtida pelo método tradicional, como por exemplo, na produção de misturas asfálticas, Ahmedzade;Sengoz (2009)[11]; Xue et al (2006) [12]; Tao et al (2019) [13], materiais cerâmicos Teo et al (2014) [14]; Badlee et al (2013) [15]; BAI et al (2010) [16]; fertilizantes Wang et al (2015) [17]; Gao et al (2015) [18], correção de solos He et al (2017) [19] e principalmente como agregados em composítos cimentícios Qiang et al (2013) [20]; Qasrawi (2014) [21]; Rondi et al (2016) [22]; Monosi et al (2016) [23]; Adegoloye et al (2016) [24].

O aproveitamento destes resíduos inertes como agregados em compósitos cimentícios deve ser investigado com cautela, em virtude que os agregados representam cerca de $60 \%$ a $80 \%$ do consumo dos materiais da argamassa pronta, em massa, resultando em significativa influência no seu comportamento no estado fresco, bem como no desempenho do revestimento endurecido [25]. Ademais, a argamassa é um produto industrial tão amplamente usado na construção civil que os fabricantes estão empenhados em encontrar substitutos de materiais mais baratos e mais disponíveis, daí a busca por produtos em sua fabricação que apresentem opções economicamente viáveis [26].

Entretanto, há uma lacuna no campo de pesquisas voltadas para o estudo da escória de aciaria do tipo BSSF na construção civil, tendo em vista que esta escória passa por um tratamento, onde, ainda no estado líquido é resfriada por meio do uso de jatos de água controlados, combinado com forças mecânicas para trituração, formando um material de característica vítrea, granulado e com baixas quantidades de cal livre [27, 28].

Pelo exposto, esta pesquisa se justifica pelo alto potencial de reaproveitamento dos resíduos da indústria siderúrgica na produção de argamassas. Tal aplicação se mostra atrativa pela possibilidade de utilização de um material em quantidade representativa e com propriedades semelhantes aos agregados naturais utilizados na construção civil, podendo-se assim, reduzir os custos de produção das argamassas, além de minimizar 
os danos ambientais ocasionados pelo consumo exarcebado de areia natural na produção de argamassas.

\section{MATERIAIS E MÉTODOS}

\subsection{Materiais}

Nesta pesquisa foi utilizado cimento Portland CP V - ARI da empresa Apodi. As Tabelas 1 e 2 apresentam as características físicas e químicas do cimento fornecidas pela empresa.

Tabela 1: Características físicas e químicas do cimento a ser utilizado

\begin{tabular}{l|l|l|l}
\hline ENSAIO & NORMA & RESULTADO & $\begin{array}{l}\text { ESPECIFICAÇÃO - NORMA } \\
\text { NBR 16697:2018 }\end{array}$ \\
\hline Perda ao fogo & NM 18/12 & $4,39 \%$ & $\leq 6,5$ \\
\hline Óxido de Magnésio - MgO & NM 11-2/12 & $4,17 \%$ & $\leq 6,5$ \\
\hline Anidrido Sulfúrico - SO3 & NM 16/12 & $3,24 \%$ & $\leq 4,5$ \\
\hline Resíduo Insolúvel & NM 15/12 & $0,69 \%$ & $\leq 3,5$ \\
\hline Anidrido Carbônico - CO2 & $11578 / 91$ & $2,97 \%$ & $\leq 5,5$ \\
\hline Massa específica & NM 23/01 & $3,06 \mathrm{~g} / \mathrm{cm}^{3}$ & Não aplicável \\
\hline Finura (\#200) & $11579 / 12$ & $0,20 \%$ & $\leq 6,0$ \\
\hline Finura (\#325) & $12826 / 14$ & $4,80 \%$ & Não aplicável \\
\hline Início de pega & NM 65/03 & $2: 15 \mathrm{~h}: \mathrm{min}$ & $\geq 1: 00 \mathrm{~h}:$ min \\
\hline Fim de pega & NM 65/03 & $3: 45 \mathrm{~h}: \mathrm{min}$ & $\leq 10: 00 \mathrm{~h}:$ min \\
\hline Expansibilidade a quente & $11582 / 16$ & $0,00 \mathrm{~mm}$ & $\leq 5,0$ \\
\hline
\end{tabular}

Tabela 2: Resistência à compressão em MPa do cimento a ser utilizado

\begin{tabular}{l|l|l}
\hline IDADE (DIAS) & MÉDIA (MPA) & ESPECIFICAÇÃO - NORMA NBR 16697:2018 \\
\hline 1 & 25,9 & $\geq 14,0 \mathrm{Mpa}$ \\
\hline 3 & 36,6 & $\geq 24,0 \mathrm{Mpa}$ \\
\hline 7 & 44,3 & $\geq 34,0 \mathrm{Mpa}$ \\
\hline 28 & 53,2 & - \\
\hline
\end{tabular}

A água utilizada foi proveniente do sistema de abastecimento público. A areia utilizada foi natural, proveniente da Região Metropolitana de Fortaleza (RMF), enquanto a escória de aciaria utilizada foi a Baosteel's Slag Short Flow (BSSF), proveniente e disponibilizada pela Companhia Siderúrgica do Pecém. O material foi seco em estufa a $105 \pm 5^{\circ} \mathrm{C}$ até a constância de massa. Após seca a escória, foi realizada o peneiramento, conforme estabelece a ABNT NBR NM 248:2003 [29].

Em seguida, foi realizado o ajuste da distribuição granulométrica da escória para se igualar ao da areia natural, no intuito de evitar influência do tamanho dos grãos na trabalhabilidade e demais propriedades das argamassas. A curva granulométrica dos agregados miúdos é apresentada na Figura 1, demonstrando que se enquadram na zona utilizável e um pequeno trecho na Zona ótima, conforme NBR 7211:2009 [30]. As características dos agregados estão descritas nas Tabelas 3 e 4 . Destaca-se que as propriedades de índice de vazios, a porosidade e o fator de empacotamento foram determinados conforme CARASEK et al. [31]. Valores próximos foram obtidos por CARASEK et al. [32] ao analisar areia natural de diâmetro máximo característico (DMC) na ordem de 2,36 mm, encontrou valores de $47 \%$ e $53 \%$ para a porosidade e fator de empacotamento, respectivamente. 


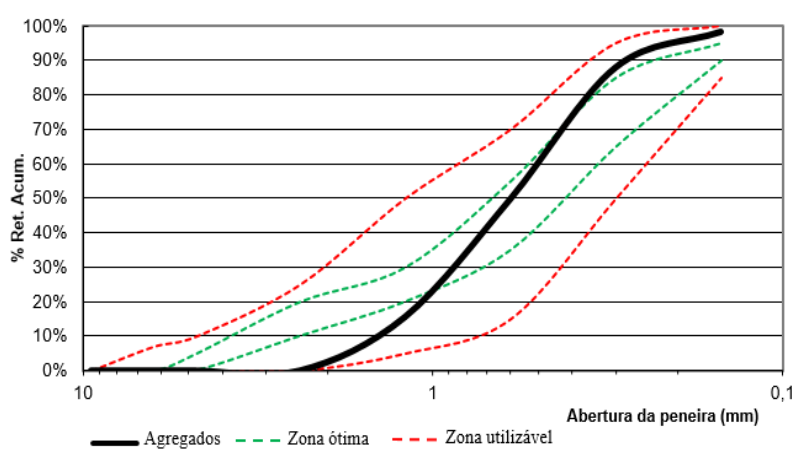

Figura 1: Curva granulométrica dos agregados.

Tabela 3: Características físicas dos agregados

\begin{tabular}{|c|c|c|c|c|}
\hline ENSAIO & NORMA/ MÉTODO & UNID & AREIA & ESCÓRIA \\
\hline DMC & ABNT NM 248: 2003 [29] & $\mathrm{mm}$ & 2,36 & 2,36 \\
\hline Módulo de finura & ABNT NM 248: 2003 [29] & Adim & 2,52 & 2,52 \\
\hline Massa unitária & $\begin{array}{l}\text { ABNT NBR NM } \quad 45: 2006 \\
{[33]}\end{array}$ & $\mathrm{g} / \mathrm{cm}^{3}$ & 1,41 & 2,08 \\
\hline Absorção de água & $\begin{array}{llll}\text { ABNT } & \text { NBR } & \text { NM } & 52: 2009 \\
{[34]} & & & \\
\end{array}$ & $\%$ & 0,9 & 2,1 \\
\hline Massa específica & $\begin{array}{llll}\text { ABNT NBR NM } & 52: 2009 \\
{[34]} & & & \\
\end{array}$ & $\mathrm{g} / \mathrm{cm}^{3}$ & 2,59 & 3,86 \\
\hline Teor de material pulverulento & $\begin{array}{l}\text { ABNT NBR NM } 46: 2003 \\
{[35]}\end{array}$ & $\%$ & 1,0 & 1,3 \\
\hline Inchamento & ABNT NBR 6467:2006 [36] & Adim & 1,44 & - \\
\hline índice de vazios, & CARASEK, 2016 et al [31] & Adim & 0,84 & 0,86 \\
\hline porosidade & CARASEK, 2016 et al [31] & $\%$ & 46 & 46 \\
\hline fator de empacotamento & CARASEK, 2016 et al [31] & $\%$ & 54 & 54 \\
\hline
\end{tabular}

Foi verificado ainda a forma dos grãos dos agregados por meio do Aggregate Image Measurement System (AIMS). Este ensaio realiza a classificação da forma dos agregados, por meio de parâmetros de forma 2D e angularidade para agregados miúdos; e angularidade, textura superficial, lamelaridade e esfericidade para agregados graúdos

Em se tratando se agregados miúdos, objeto de estudo deste trabalho, a forma 2D quantifica a forma relativa de imagens bidimensionais das partículas de agregado, tendo o valor variando em uma escala de 0 a 20, sendo o mais próximo de zero, mais a partícula de agregado terá a forma de um círculo perfeito. Já quanto a angularidade quantifica as mudanças ao longo das bordas das partículas e varia em uma escala de 0 a 10.000. De acordo com esse parâmetro, um círculo perfeito tem um valor de gradiente de angularidade muito baixo, tendendo a zero [37].

Ressalta-se que apesar do agregado miúdo ter sido utilizado passante na peneira $2,36 \mathrm{~mm}$, foi realizado a análise das partículas retidas na peneira $4,75 \mathrm{~mm}$, o qual é considerado agregado graúdo, para se conhecer a textura dos grãos de escória de aciaria. A classificação utilizada foi a proposta por AL ROUSAN [38].

Tabela 4: Classificação dos agregados pelo AIMS

\begin{tabular}{l|l|l|l|l|l}
\hline PARÂMETRO & \multicolumn{5}{l}{ LIMITES / CLASSIFICAÇÃO (adimensional) } \\
\hline \multirow{2}{*}{ Forma 2D } & $<6,5$ & $6,5-8,0$ & $8,0-10,5$ & $>10,5$ & - \\
\cline { 2 - 6 } & Circular & Semicircular & Semialongado & Alongado & - \\
\hline \multirow{2}{*}{ Angularidade } & $<2100$ & $2100-4000$ & $4000-5400$ & $>5400$ & - \\
\cline { 2 - 6 } & Arredondado & Subarredondado & Subangular & Angular & - \\
\hline
\end{tabular}




\begin{tabular}{l|l|l|l|l|l}
\hline \multirow{2}{*}{ Textura superficial } & $<165$ & $165-275$ & $275-350$ & $350-460$ & $>460$ \\
\cline { 2 - 6 } & Polido & Macio & $\begin{array}{l}\text { Baixa } \\
\text { rugosidade }\end{array}$ & $\begin{array}{l}\text { Rugosidade } \\
\text { moderada }\end{array}$ & $\begin{array}{l}\text { Alta } \\
\text { rugosidade }\end{array}$ \\
\hline \multirow{3}{*}{ Esfericidade } & $<0,6$ & $0,6-0,7$ & $0,7-0,8$ & $>0,8$ & - \\
\cline { 2 - 6 } & $\begin{array}{l}\text { Achatado/ } \\
\text { alongada }\end{array}$ & $\begin{array}{l}\text { Baixa } \\
\text { effericidade }\end{array}$ & $\begin{array}{l}\text { Esfericidade } \\
\text { moderada }\end{array}$ & $\begin{array}{l}\text { Alta } \\
\text { esfericidade }\end{array}$ & - \\
\hline
\end{tabular}

A Tabela 5 apresenta a classificação da areia e da escória de aciaria.

Tabela 5: Resumo da classificação dos agregados pelo AIMS

\begin{tabular}{l|l|l|l|l|l}
\hline \multirow{2}{*}{ PARÂMETRO } & \multirow{2}{*}{$\begin{array}{c}\text { TIPO DE } \\
\text { AGREGADO }\end{array}$} & \multicolumn{2}{l}{ TRATAMENTO ESTATíSTICO (adimensional) } & \multirow{2}{*}{ CLASSIFICAÇÃO } \\
\cline { 3 - 7 } & MÉDIA & No DE PARTíCULAS & DESVIO PADRÃO & \\
\hline \multirow{3}{*}{ Forma 2D } & Areia natural & 7,7 & 909 & 1,9 & Semicircular \\
\cline { 2 - 6 } & Escória & 8,0 & 895 & 2,4 & Semicircular \\
\hline \multirow{3}{*}{ Angularidade } & Areia natural & 3490,8 & 961 & 1216,9 & Subarredondada \\
\cline { 2 - 6 } & Escória & 3650,3 & 948 & 1486,7 & Subarredondada \\
\hline \multirow{2}{*}{ Textura } & Areia natural & 135,9 & 50 & 53,4 & Polido \\
\cline { 2 - 6 } & Escória & 297,6 & 50 & 117,7 & Baixa rugosidade \\
\hline
\end{tabular}

Em relação a caracterização química da escória de aciaria, foi realizado a Fluorescência de raio X (FRX), apresentado na Tabela 6. Constata-se que a escória é constituída basicamente de Fe2O3, $\mathrm{CaO}$ e $\mathrm{SiO} 2$ $( \pm 92 \%)$, o qual valores próximos foram obtidos por CAMPOS et al [39] utilizando a mesma escória proveniente da Companhia Siderúrgica do Percém (CSP).

Tabela 6: Composição química da escória de aciaria BSSF

\begin{tabular}{l|l}
\hline óxidOS & $\begin{array}{l}\text { AMOSTRA } \\
(\%)\end{array}$ \\
\hline $\mathrm{Al}_{2} \mathrm{O}_{3}$ & 0,63 \\
$\mathrm{SiO}_{2}$ & 5,84 \\
$\mathrm{P}_{2} \mathrm{O}_{5}$ & 1,01 \\
$\mathrm{~K}_{2} \mathrm{O}$ & 0,04 \\
$\mathrm{CaO}$ & 33,46 \\
$\mathrm{TiO}_{2}$ & 0,63 \\
$\mathrm{Cr}_{2} \mathrm{O}_{3}$ & 0,21 \\
$\mathrm{MnO}$ & 5,09 \\
$\mathrm{Fe}_{2} \mathrm{O}_{3}$ & 52,98 \\
$\mathrm{Co}_{2} \mathrm{O}_{3}$ & 0,12 \\
\hline
\end{tabular}

\subsection{Métodos}

Foram empregados os traços 1:3 (A), 1:5 (B) e 1:7 (C) (cimento: agregado) de argamassas de cimento Portland e 1:1:4 (D), 1:1:6 (E) e 1:1:8 (F) (cimento: cal: agregado) de argamassas mistas, em proporções de massa combinado com volume. Por exemplo, o traço 1:5 constitui de 50kg de cimento (1 saco de cimento) e 5 padiolas de areia úmida de 40L cada, e assim respectivamente para os demais. A relação a/c (água/cimento) foi determinado por meio do ensaio de flow-table [40], fixando-se o índice de consistência em $260 \pm 5 \mathrm{~mm}$. Em seguida, estes traços foram transformados em massa por meio da massa unitária, no intuito de melhorar a realização dos ensaios no laboratório. Destaca-se ainda que foi utilizado o inchamento da areia para a conversão do traço de obra utilizado em volume para massa, o qual foi utilizado no laboratório. 
A substituição da areia natural por escória de aciaria ocorreu em volume, conforme a equação 01, sendo m (a massa do material) e $\gamma$ (massa específica do material). A areia foi substituída pela escória de aciaria nos teores de $0,20,40$ e $60 \%$. A Tabela 7 apresenta as proporções dos traços analisados, sendo o consumo de água definido conforme a NBR 13276:2016 [40].

$$
\text { Mescória }=\text { Mareia } \frac{\text { Yescória }}{\text { Xareia }}
$$

Tabela 7: Proporção dos traços ensaiados

\begin{tabular}{|c|c|c|c|c|c|c|c|c|c|c|c|c|}
\hline \multirow{2}{*}{ TRAÇO } & \multirow{2}{*}{ IDENT } & \multicolumn{5}{|c|}{ TRAÇO UNITÁRIO EM MASSA } & \multicolumn{5}{|c|}{ CONSUMO EM KG/M³ } & \multirow{2}{*}{$\begin{array}{c}\text { TEOR DE } \\
\text { AR (\%) }\end{array}$} \\
\hline & & Cimento & $\mathrm{Cal}$ & Areia & Escória & Água & Cimento & $\mathrm{Cal}$ & Areia & Escória & Água & \\
\hline \multirow{4}{*}{ A } & AREF & 1 & 0 & 2,35 & 0 & 0,52 & 570,1 & 0 & 1339,7 & 0 & 296,4 & 3 \\
\hline & A 20 & 1 & 0 & 1,88 & 0,7 & 0,54 & 563,7 & 0 & 1059,7 & 394,6 & 304,4 & 1 \\
\hline & A40 & 1 & 0 & 1,41 & 1,4 & 0,56 & 557,4 & 0 & 786 & 780,4 & 312,2 & 2 \\
\hline & A60 & 1 & 0 & 0,94 & 2,1 & 0,55 & 560,6 & 0 & 527 & 1177,3 & 308,3 & 2 \\
\hline \multirow{4}{*}{ B } & BREF & 1 & 0 & 3,92 & 0 & 0,83 & 374,5 & 0 & 1468 & 0 & 310,8 & 4 \\
\hline & B20 & 1 & 0 & 3,13 & 1,17 & 0,85 & 372 & 0 & 1164,3 & 435,2 & 316,2 & 3 \\
\hline & B40 & 1 & 0 & 2,35 & 2,33 & 0,88 & 368 & 0 & 864,7 & 857,3 & 323,8 & 4 \\
\hline & B60 & 1 & 0 & 1,57 & 3,5 & 0,9 & 365 & 0 & 573,1 & 1277,5 & 328,5 & 3 \\
\hline \multirow{4}{*}{$\mathrm{C}$} & CREF & 1 & 0 & 5,48 & 0 & 1,19 & 275,3 & 0 & 1508,5 & 0 & 327,6 & 4 \\
\hline & $\mathrm{C} 20$ & 1 & 0 & 4,39 & 1,63 & 1,24 & 271,4 & 0 & 1191,6 & 442,4 & 336,6 & 5 \\
\hline & $\mathrm{C} 40$ & 1 & 0 & 3,29 & 3,27 & 1,33 & 265 & 0 & 871,7 & 866,4 & 352,4 & 4 \\
\hline & C60 & 1 & 0 & 2,19 & 4,9 & 1,32 & 265,8 & 0 & 582,2 & 1302,6 & 350,9 & 3 \\
\hline \multirow{4}{*}{$\mathrm{D}$} & REFD & 1 & 0,4 & 3,13 & 0 & 0,79 & 403 & 161,2 & 1261,3 & 0 & 403,8 & 2 \\
\hline & D20 & 1 & 0,4 & 2,51 & 0,93 & 0,8 & 401,1 & 160,4 & 1006,8 & 373 & 401,9 & 2 \\
\hline & D40 & 1 & 0,4 & 1,88 & 1,87 & 0,81 & 399,4 & 159,8 & 751 & 747 & 400,3 & 2 \\
\hline & D60 & 1 & 0,4 & 1,25 & 2,8 & 0,8 & 401,4 & 160,6 & 501,8 & 1124 & 402,2 & 3 \\
\hline \multirow{4}{*}{$\mathrm{E}$} & REFE & 1 & 0,4 & 4,7 & 0 & 1,07 & 296,9 & 118,8 & 1395,6 & 0 & 298 & 4 \\
\hline & E20 & 1 & 0,4 & 3,76 & 1,4 & 1,08 & 296,1 & 118,4 & 1113,2 & 414,5 & 297,2 & 3 \\
\hline & $\mathrm{E} 40$ & 1 & 0,4 & 2,82 & 2,8 & 1,1 & 294,4 & 117,7 & 830,1 & 824,2 & 295,5 & 3 \\
\hline & E60 & 1 & 0,4 & 1,88 & 4,2 & 1,09 & 295,2 & 118,1 & 555,1 & 1240 & 296,3 & 4 \\
\hline \multirow{4}{*}{$F$} & REFF & 1 & 0,4 & 6,27 & 0 & 1,38 & 233,4 & 93,4 & 1463,6 & 0 & 234,8 & 4 \\
\hline & F20 & 1 & 0,4 & 5,01 & 1,87 & 1,41 & 231,9 & 92,8 & 1161,91 & 433,7 & 233,3 & 5 \\
\hline & $\mathrm{F} 40$ & 1 & 0,4 & 3,76 & 3,74 & 1,45 & 229,7 & 91,9 & 863,634 & 859 & 231,1 & 5 \\
\hline & F60 & 1 & 0,4 & 2,51 & 5,6 & 1,56 & 224,1 & 89,6 & 562,4 & 1254,8 & 225,6 & 4 \\
\hline
\end{tabular}

Após a determinação dos traços, foi realizada a preparação das argamassas, seguindo os procedimentos preconizados pela NBR 16541:2016 [41]. Após a mistura, determinou-se o teor de ar incorporado das argamassas pelo método gravimétrico, conforme NBR 13280:2005 [42]. Em seguida, foram realizados a moldagem dos corpos de prova prismáticos de 4 x 4 x $16 \mathrm{~cm}$ para os ensaios de caracterização das argamassas no estado endurecido a idade de 28 dias.

A resistência à compressão e a tração na flexão foi realizada conforme NBR 13279:2005 [43], tendo sido realizado 3 amostras para a flexão e 6 para a compressão. A determinação da massa específica aparente no estado endurecido foi realizada em 3 corpos de prova, seguindo os procedimentos da NBR 13280:2005 [42].

O módulo de elasticidade dinâmico (Ed) foi determinando conforme a NBR 15630:2008 [44]. Para este 
ensaio foram realizadas 3 determinações em corpos de provas distintos. Primeiramente, determinou-se a velocidade de propagação ultrassônica (VPU) por meio do equipamento Pundit Lab+, com frequência dos transdutores na ordem de $54 \mathrm{~Hz}$, conforme Equação 2, sendo L a distância entre os pontos de acoplamento dos transdutores (comprimentos do corpo de prova, em $\mathrm{mm}$ ) e $\mathrm{t}$ - o tempo registrado pelo mostrador digital, em $\mu \mathrm{s}$.

$$
V P L=L / t
$$

Em seguida. O módulo de elasticidade dinâmico foi determinado conforme Equação 3.

$$
E d=\rho \cdot v^{2} \cdot \frac{(1+\mu) \cdot(1-2 \mu)}{1-\mu}
$$

Sendo:

$\rho$ - densidade de massa aparente no estado endurecido da argamassa $\left(\mathrm{kg} / \mathrm{m}^{3}\right)$

$\mathrm{v}$ - velocidade de propagação ultrassônica $(\mathrm{mm} / \mu \mathrm{s})$

$\mu$ - coeficiente de Poisson, sendo usualmente 0,20 nesta equação.

Para o tratamento dos dados, foi realizado por meio de análise estatística, com a realização da Análise de variância (ANOVA) no software Statistic ${ }^{\circledR}$ 7.0. Primeiramente, realiza-se os resíduos padronizados para os ensaios realizados, no intuito de eliminar os dados espúrios. Tais valores são considerados outliers quando os resíduos padronizados excedem um valor de referência de 1,96 para mais ou para menos (valor crítico para um nível de confiança de 0,05). Após a identificação e descarte dos dados discrepantes foi realizado uma nova rodada de análise no software Statistic ${ }^{\circledR}$ até que todos os pontos fiquem compreendidos no intervalo como aceitável. Por fim, com todos os valores dentro dos limites aceitáveis é realizado a ANOVA para identificar a significância ou não dos resultados obtidos.

\section{RESULTADOS E DISCUSSÕES}

As Figura 2 e 3 apresenta a comportamento do teor de substituição da areia natural por escória de aciaria BSSF na resistência à compressão e a tração na flexão das argamassas respectivamente. Pode-se constatar pela Figura 2 que o teor de substituição não exerce influência na resistência à compressão. Apesar de haver uma tendência ao aumento da resistência a tração na flexão, com destaque para o teor de $40 \%$ (Figura 3), o teor de substituição não exerce influência significativa na resistência a tração na flexão.
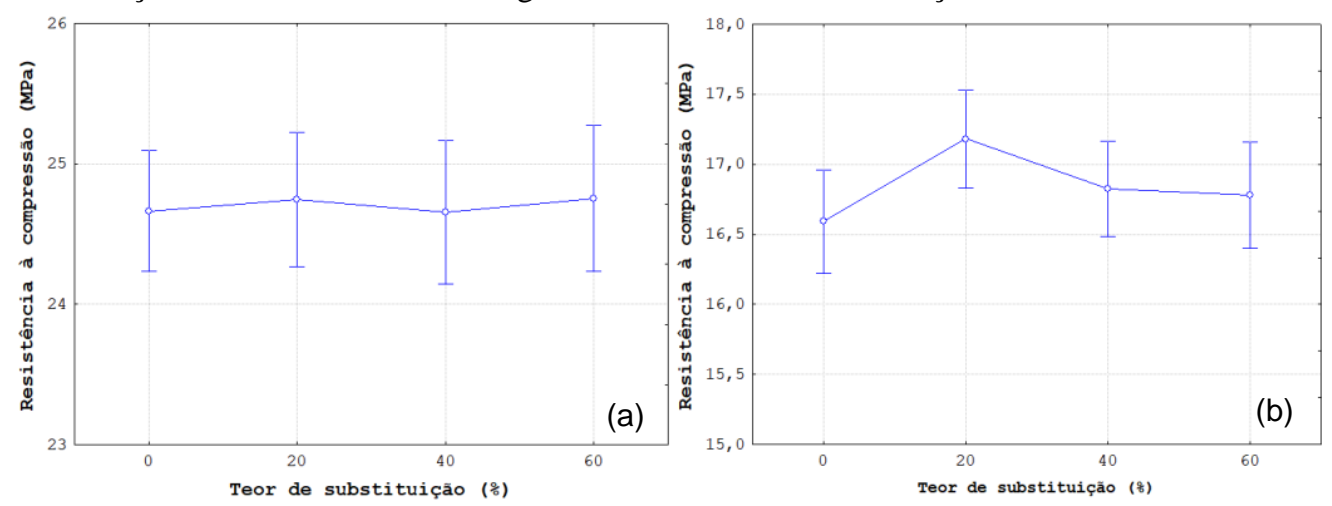

Figura 2: Influência do teor de substituição resistência à compressão das argamassas; a) de cimento Portland e b) mistas 

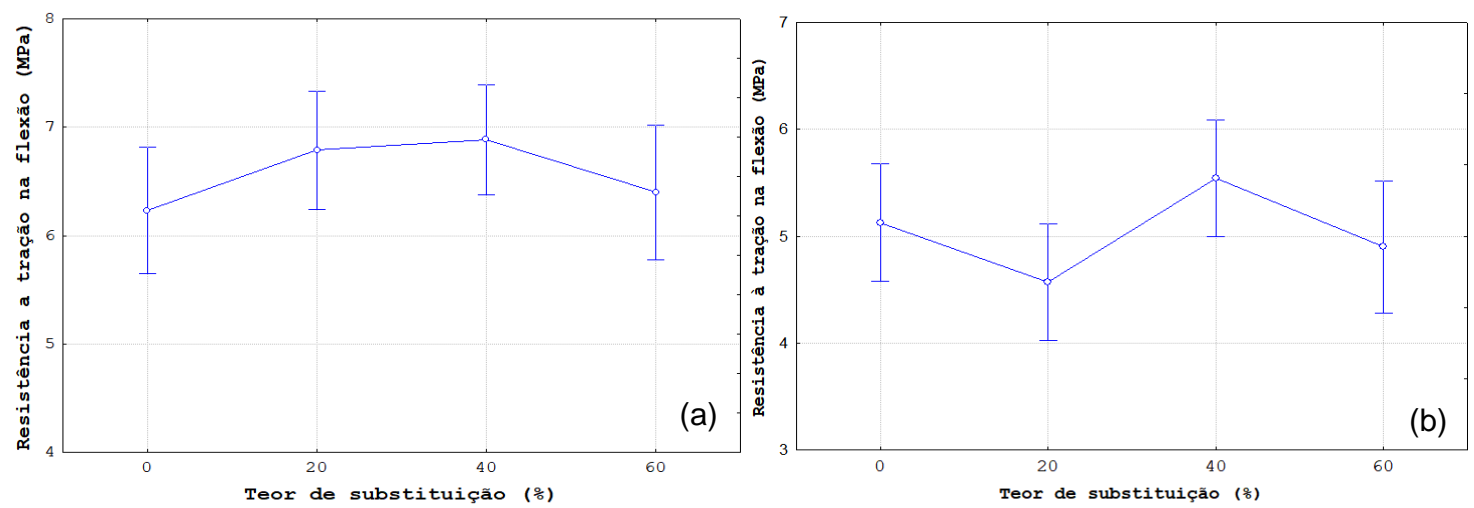

Figura 3: Influência do teor de substituição resistência à tração na flexão das argamassas; a) de cimento Portland e b) mistas

A análise de variância constatou, com 95\% de confiabilidade, que para argamassas de cimento Portland e mistas, o teor de substituição não exerce influência na resistência à compressão para ambos os tipos de argamassa, tendo influência apenas o traço e a interação teor-traço.

Em se tratando da resistência à tração na flexão, a análise de variância também constatou que o teor de substituição não exerce influência significativa para as argamassas de cimento Portland e mistas, tendo influência apenas o traço e a interação teor-traço.

As Figuras 4 e 5 apresentam os valores de resistência à compressão para cada teor de substituição de acordo com cada traço.

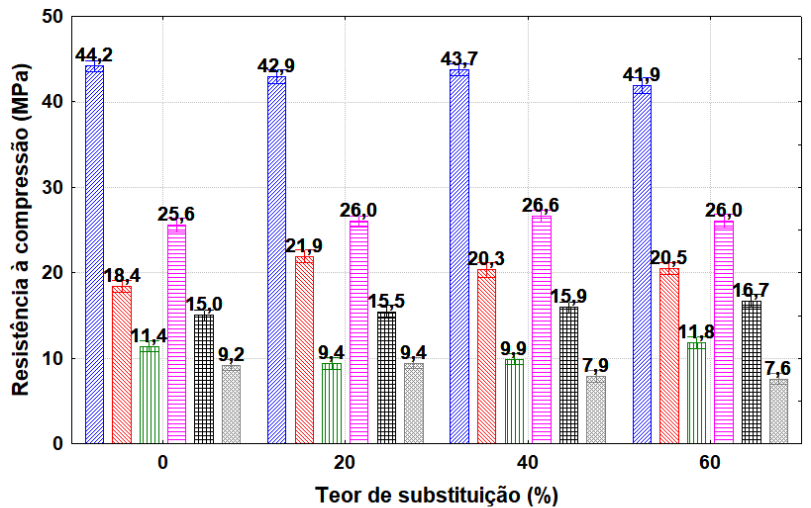

Wreas Traço 1:3 Traço 1:5

Figura 4: Resistência à compressão das argamassas de cimento Portland e mistas.

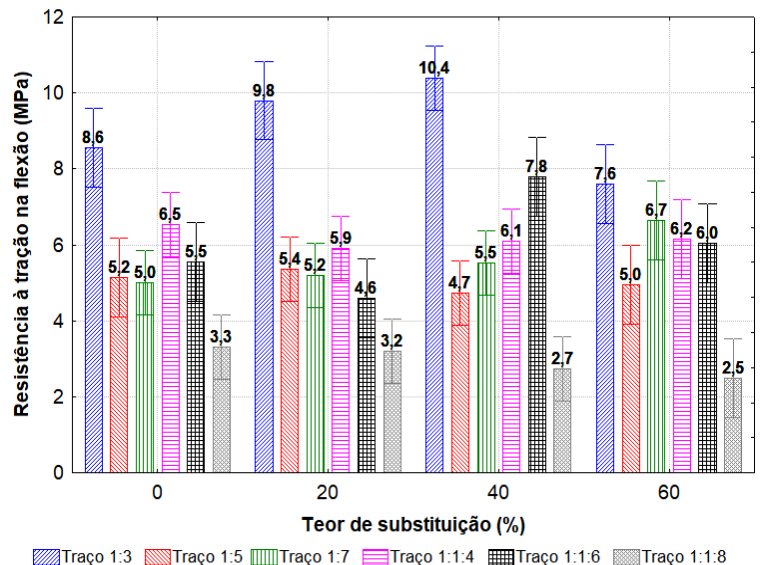

Figura 5: Resistência a tração na flexão das argamassas de cimento Portland e mistas 
Conforme observado na Figura 4 apesar de haver uma tendência de redução da resistência à compressão para o traço 1:3 e 1:1:8 e um aumento para o traço 1:5 e 1:1:6, a análise de variância demonstrou que não ocorre influência da resistência com o aumento do teor de escória, mesmo com as argamassas com escória tendo apresentado maior fator a/c.

Estudos realizados $[45,46]$ constataram aumento da resistência à compressão e a tração na flexão com o aumento de escória. Isto pode ser justificado pela forma irregular dos grãos de escória, há um melhor intertravamento entre a pasta de cimento e os grãos de escória, melhorando a zona de transição [47, 48, 49].

Fato contrário foi constatado por LACERDA [50], que concluiu que a resistência à compressão da argamassa com agregado de escória foi inferior à argamassa de referência em até em $35 \%$ em 7 dias e $12 \%$ em 28 dias. Entretanto, no referido trabalho não houve o ajuste granulométrico dos agregados, o que deve ter influenciado nas propriedades mecânicas das argamassas.

Apesar de haver uma tendência do aumento da resistência à compressão com o aumento da resistência a tração na flexão, a correlação linear apresentou um valor de $\mathrm{R}^{2}$ na ordem de 0,69 (Figura 6). Quanto a classificação conforme a NBR 13281:2005 [51] das argamassas ensaiadas, todas as argamassas investigadas enquadram-se nas mesma categorias de resistência mecânica:R6 (resistência à compressão > 3,5 MPa) e P6 (resistência à tração na flexão > 8,0 MPa).

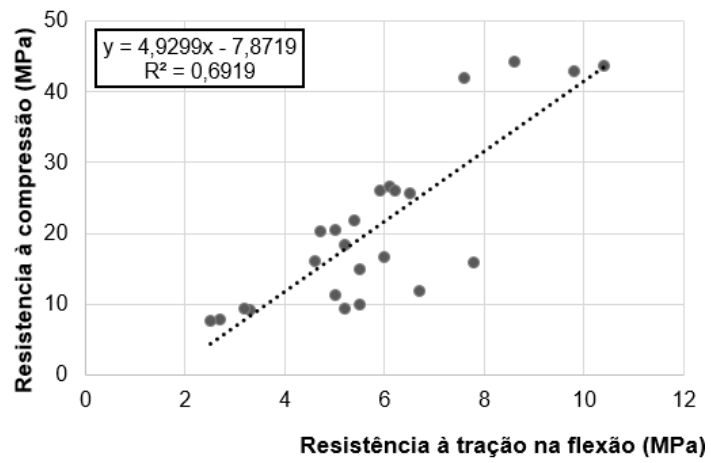

Figura 6: Correlação entre a resistência à compressão e a resistência a tração na flexão.

Em relação a massa específica aparente das argamassas, quanto maior a porcentagem de substituição de escória pela areia, maior a massa específica obtida, como pode ser observado na Figura 7. Isso se deve ao fato da massa específica da escória de aciaria ser maior que a da areia [34, 39, 52]. O teste de análise de variância identificou que o teor de substituição exerce influência significativa na massa especifica aparente do estado endurecido das argamassas de cimento Portland e mistas.
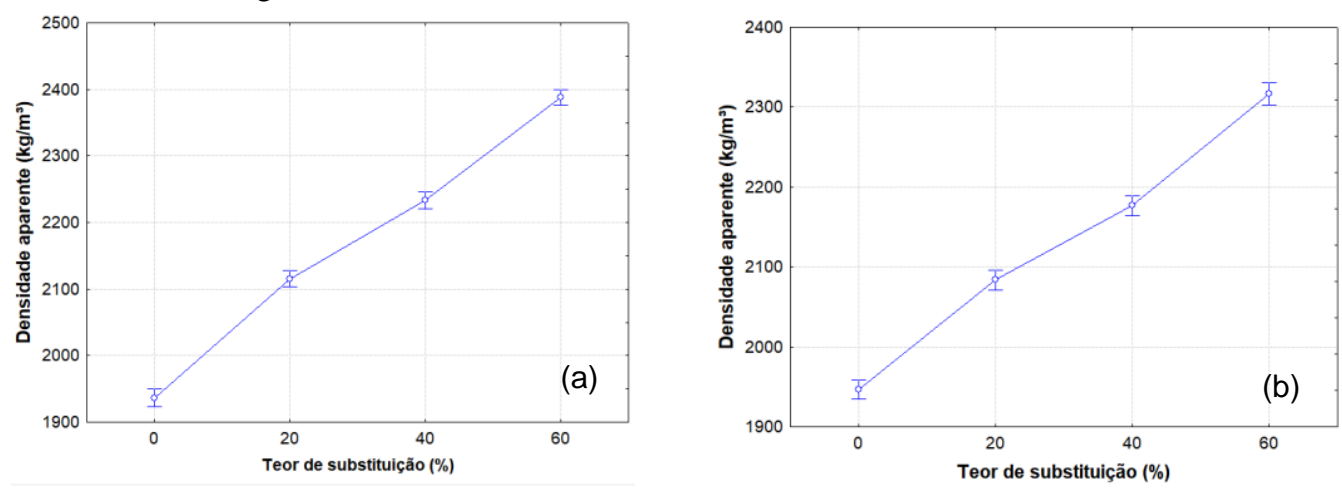

Figura 7: a) Influência do teor de substituição na densidade das argamassas: a) de cimento Portland e b) mistas

Foi possível estabelecer uma ótima correlação linear entre a massa específica no estado endurecido e o teor de substituição das argamassas com $\mathrm{R}^{2}$ na ordem de 0,83 e 0,89, respectivamente para as argamassas de cimento Portland e mistas, conforme ilustrado na Figura 8. 

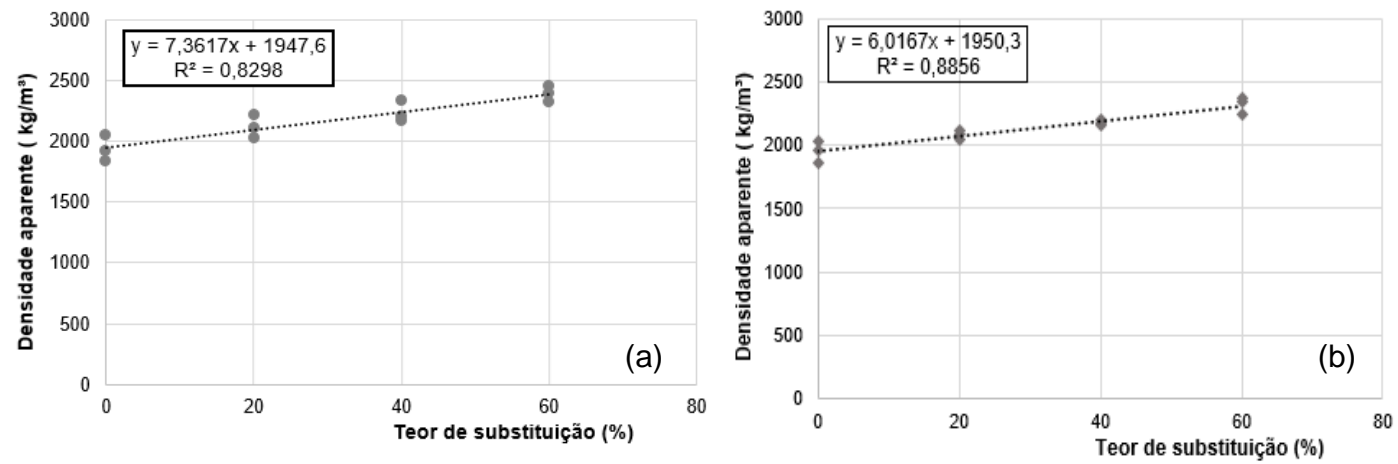

Figura 8: Correlação entre o teor de substituição e a densidade no estado endurecido das argamassas: a) de cimento Portland ; e b) mistas

A influência das proporções de materiais utilizados na massa especifica se deve, principalmente, pela maior quantidade de cimento em determinados traços (traços ricos), que, devido a sua maior massa especifica em relação ao agregado natural, ocasiona um aumento na massa específica. Efeito notável na figura 9, que apresenta o comportamento da massa específica aparente no estado endurecido conforme o teor de substituição do agregado natural nas argamassas de cimento Portland e mistas.
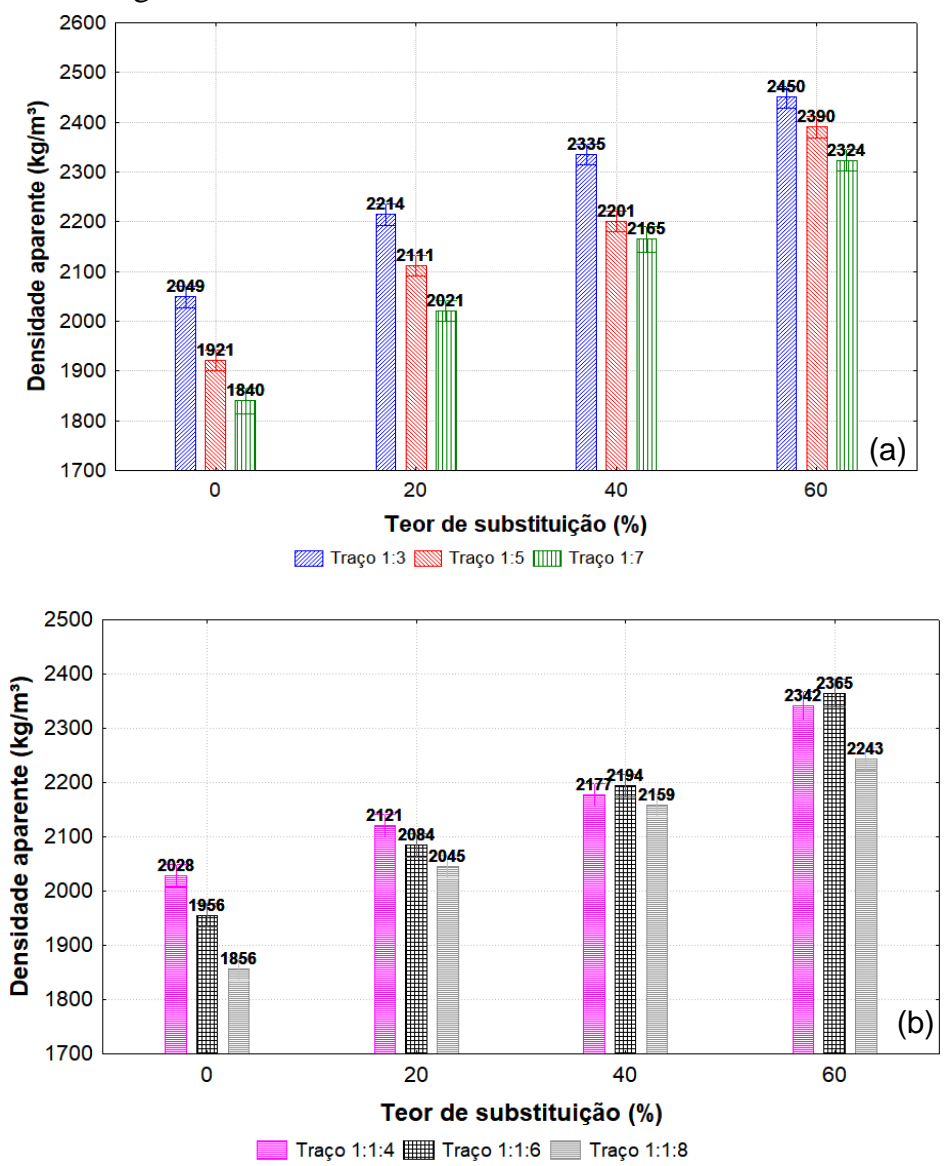

Figura 9: Densidade no estado endurecido das argamassas de acordo com o traço e o teor de substituição: a) de cimento Portland; b) mistas.

Em relação a classificação conforme a NBR 13281:2005 [51], quanto a massa específica aparente no estado endurecido $\left(\mathrm{kg} / \mathrm{m}^{3}\right)$ apesar de haver um aumento da massa específica, todas as argamassas investigadas enquadram-se na mesma categoria, classe M6 (massa específica aparente no estado endurecido > 1800 $\mathrm{kg} / \mathrm{m} 3$ ). Entretanto, conforme a classificação proposta por CARASEK [25], estabelece que as massas específicas compreendidas entre $1,40 \mathrm{~g} / \mathrm{cm}^{3}$ a $2,30 \mathrm{~g} / \mathrm{cm}^{3}$ são classificadas como normais, enquanto que massas 
específicas superiores a 2,30 g/ $\mathrm{cm}^{3}$ são classificadas como pesada. Com isto, tem-se que as argamassas com o teor de $60 \%$ de substituição da areia natural por escória de aciaria são classificadas como argamassa pesada.

Em relação a VPU, a ANOVA constatou que o teor de substituição não influencia significativamente na VPU das argamassas de cimento Portland (Figura 10), em contrapartida, exerce influência nas argamassas mistas (Figura 11).
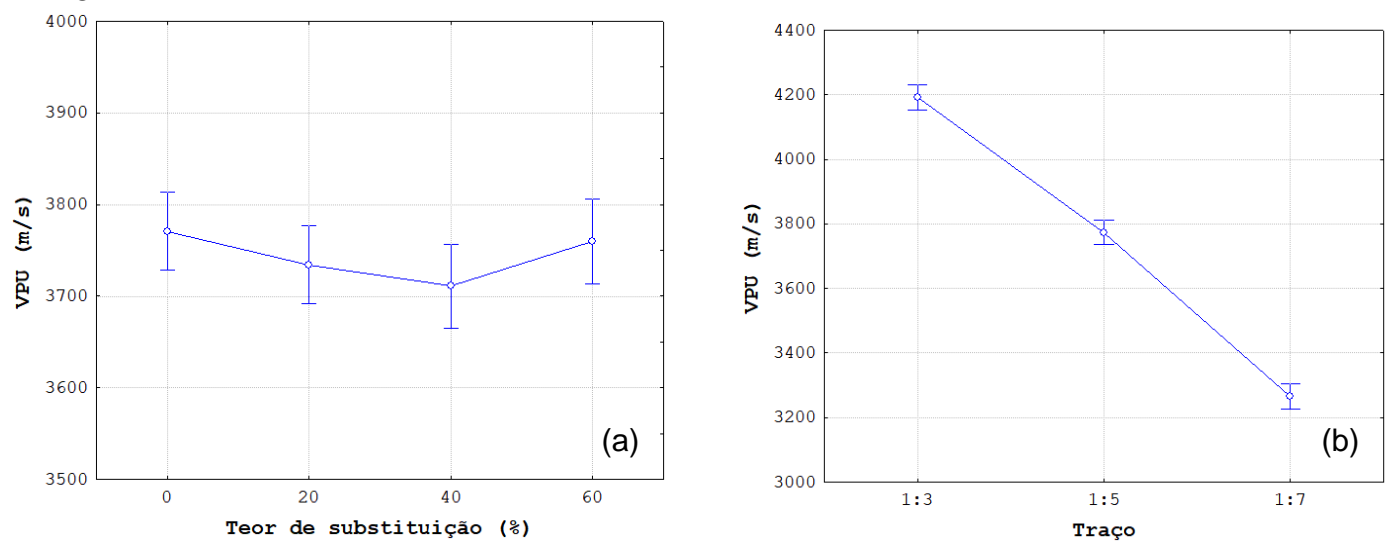

Figura 10: a) Influência do teor de substituição na VPU das argamassas de cimento Portland ; b) Influência do traço na VPU das argamassas de cimento Portland .
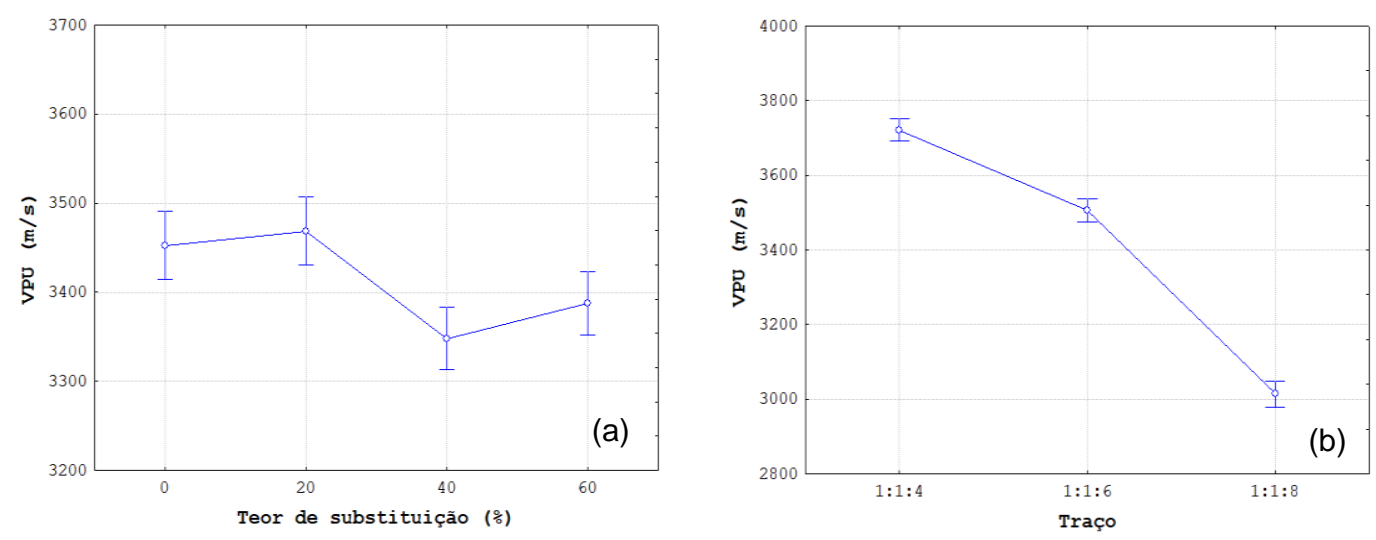

Figura 11: a) Influência do teor de substituição na VPU das argamassas mistas; b) Influência do traço na VPU das argamassas mistas

Quanto a VPU, pode-se constatar com a análise de variância que para as argamassas de cimento Portland e mistas, o traço não exerce influência significativa na VPU das argamassas. A Figura 12 apresenta o comportamento da VPU conforme o teor de substituição para os traços investigados. Apesar das argamassas com escória apresentarem maior fator a/c, o que influencia na porosidade da argamassa, e consequentemente na VPU, a ANOVA constatou que a substituição não afeta significativamente tal propriedade. 


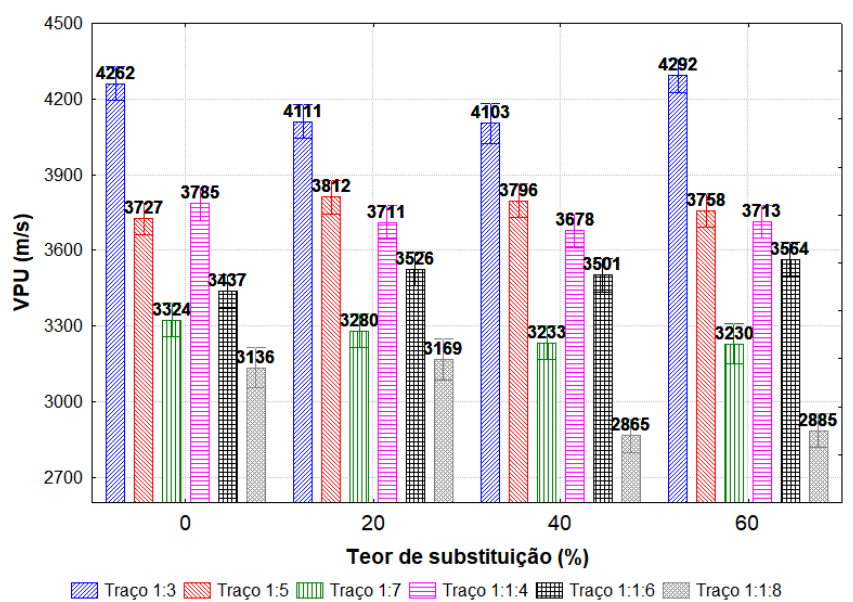

Figura 12: VPU das argamassas de cimento Portland e mistas de acordo com o traço e o teor de substituição.

Foi possível verificar que o aumento do consumo de cimento influencia no aumento da VPU para as argamassas de cimento Portland, e o aumento do consumo de cal $\left(\mathrm{kg} / \mathrm{m}^{3}\right)$ para as argamassas mistas, sendo encontrado valores de correlação $R^{2}$ na ordem de 0,93 e 0,82 respectivamente.
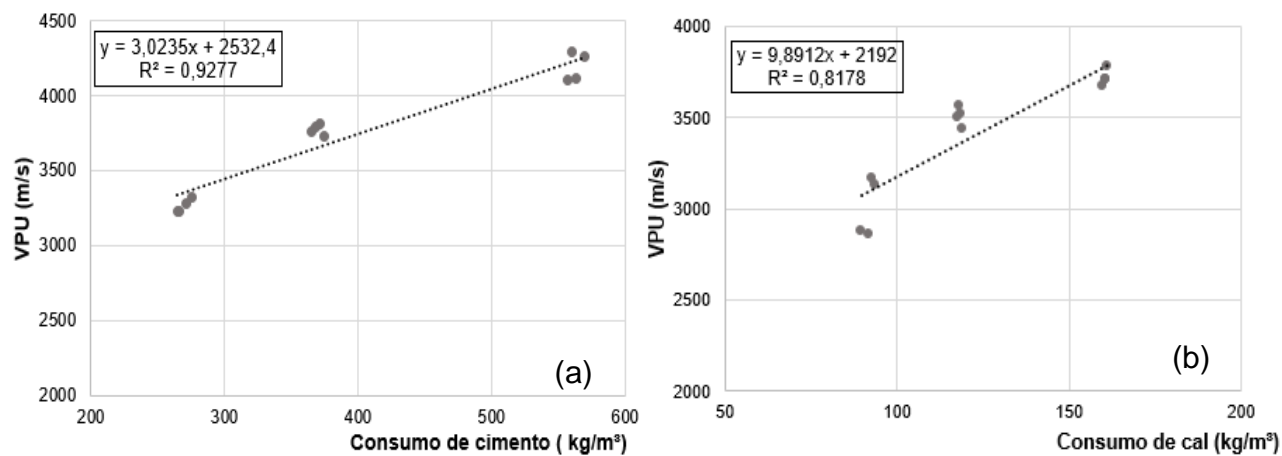

Figura 13: a) Correlação entre a VPU e o consumo de cimento das argamassas de cimento Portland ; b) Correlação entre a VPU e o consumo de cal das argamassas mistas.

Em se tratando do módulo de elasticidade dinâmico, as Figuras 14 e 15 demonstra a influência do teor de substituição de areia natural por escória de aciaria, bem como do traço no módulo de elasticidade dinâmico para as argamassas de cimento Portland e mistas. Com o teste da ANOVA, constata-se que o teor de substituição e o traço exercem influência no módulo dinâmico.
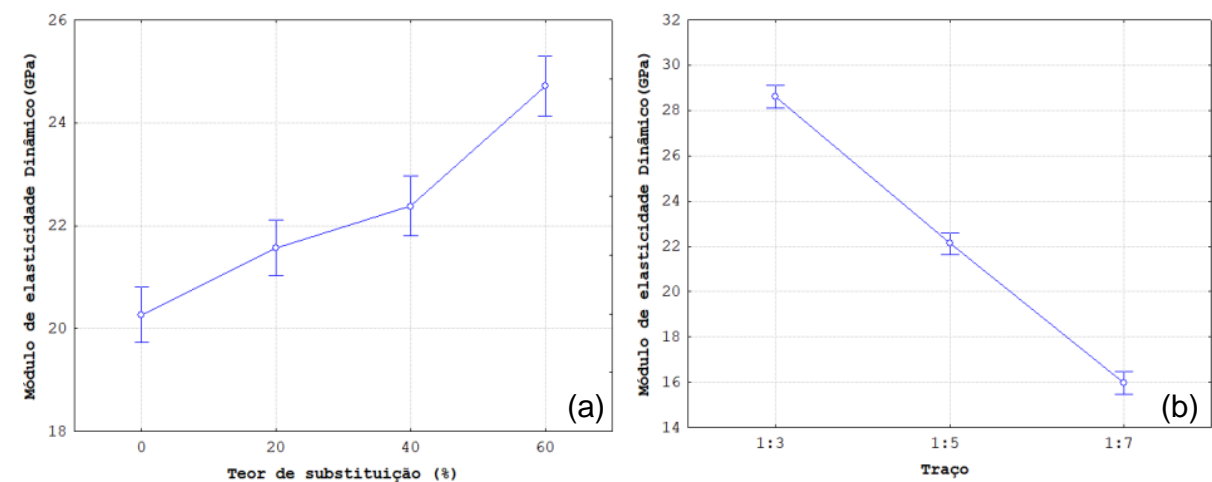

Figura 14: a) Influência do teor de substituição no módulo de elasticidade dinâmico das argamassas de cimento Portand; b) Influência do traço no módulo de elasticidade dinâmico das argamassas de cimento Portland. 

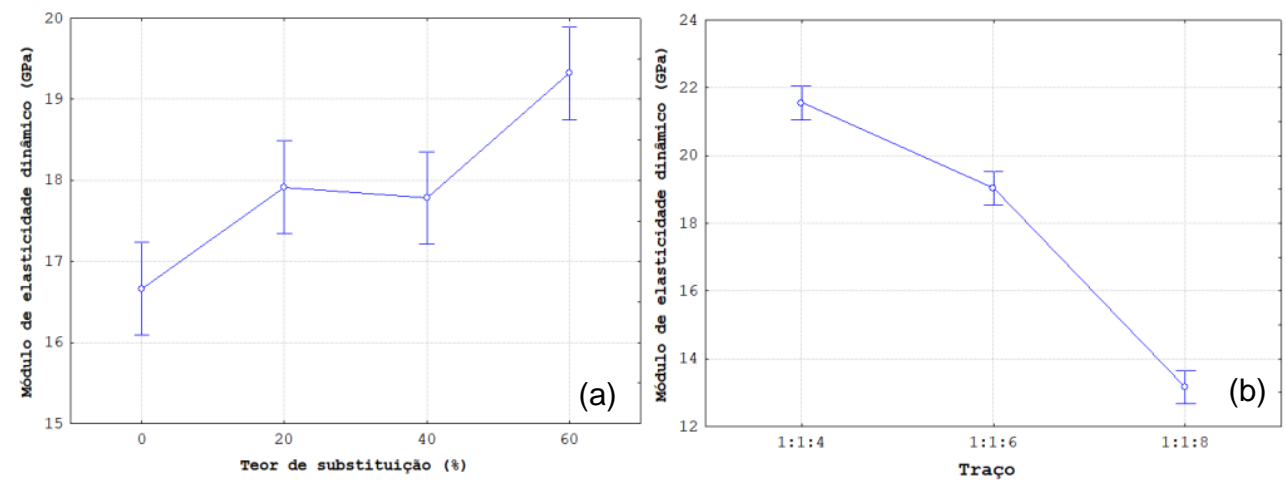

Figura 15: a) Influência do teor de substituição no módulo de elasticidade dinâmico das argamassas mistas; b) Influência do traço no módulo de elasticidade dinâmico das argamassas mistas.

A Figura 16 apresenta o comportamento do módulo de elasticidade dinâmico das argamassas de acordo com o traço e teor de substituição. O módulo de elasticidade dinâmico apresentou valores elevados, sendo os traços com maiores consumos de cimento os que apresentaram os maiores valores de módulo de elasticidade, devido ao aumento da rigidez. Outra justificativa para os altos valores do módulo de elasticidade se deve ao baixo teor de ar das argamassas. As bolhas de ar aumentaram a capacidade de deformação da argamassa e reduzem sua rigidez [53]. Ao passo que conforme a Tabela 7, os valores de teor de ar ficaram compreendidos entre 1 e 5\%. Para argamassas de revestimento produzidas sem aditivos, seja argamassas simples ou mistas, o teor de ar geralmente encontra-se em torno de 2 a $5 \%$ do volume total [54].

Constata-se que apesar das argamassas com maior teor de substituição apresentarem maior fator a/c, se comparadas com as argamassas de referência, as mesmas apresentam maior valor de módulo de elasticidade dinâmico. Isto se deve, possivelmente, devido a massa específica da escória $\left(3,86 \mathrm{~g} / \mathrm{cm}^{3}\right)$ ser superior ao da areia natural $\left(2,59 \mathrm{~g} / \mathrm{cm}^{3}\right)$. Em adição, estudos indicam que dureza do agregado de escória de aciaria é similar ou superior à de agregados de origem quartzosa e granítica [55, 56] LUXAN et al., 2000). Tais características favorecem o aumento do módulo de elasticidade dinâmico das argamassas com maiores teores de escória de aciaria BSSF. No mesmo sentido, CARRIJO [45], em estudo experimental constatou que concretos com agregados mais densos tendem a gerar concretos com maiores valores de módulo de elasticidade.

Os altos valores obtidos podem prejudicar a durabilidade do revestimento, ao passo que quanto menor o valor do módulo, maior será a capacidade do revestimento de absorver deformações [58,59]. Logo, argamassas com maiores valores de módulo de elasticidade dinâmico são mais propensas a fissuração, podendo afetar a estanqueidade e consequentemente a vida útil do revestimento.

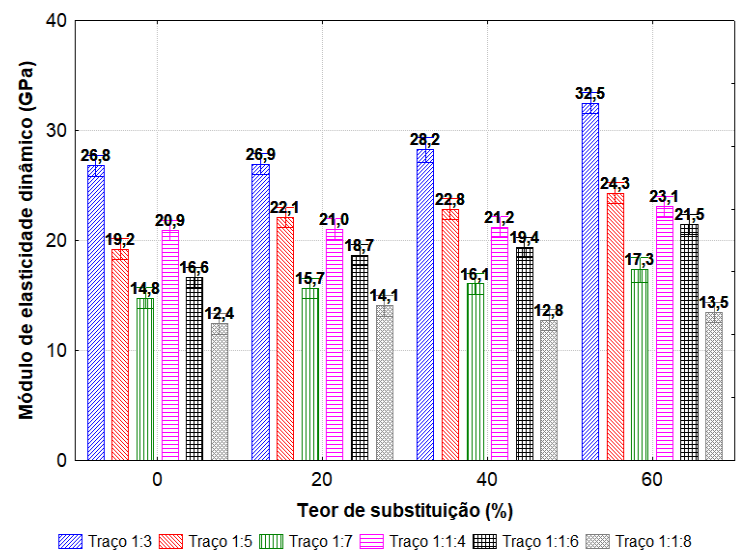

Figura 16: Módulo dinâmico das argamassas de cimento Portland de acordo com o traço e o teor de substituição.

Foi possível ainda estabelecer a correção linear entre o teor de substituição e o módulo de elasticidade dinâmico das argamassas (Figura 17 e 18). Sendo encontrado valores de coeficiente de determinação $\left(\mathrm{R}^{2}\right)$ na ordem $0,79,0,93$ e 0,96 respectivamente para os traços 1:3, 1:5 e 1:7. Quanto as argamassas mistas, os coeficientes de determinação $\left(\mathrm{R}^{2}\right)$ na ordem $0,71,0,96$ e 0,12 respectivamente para os traços 1:1:4, 1:1:6 e 1:1:8. 


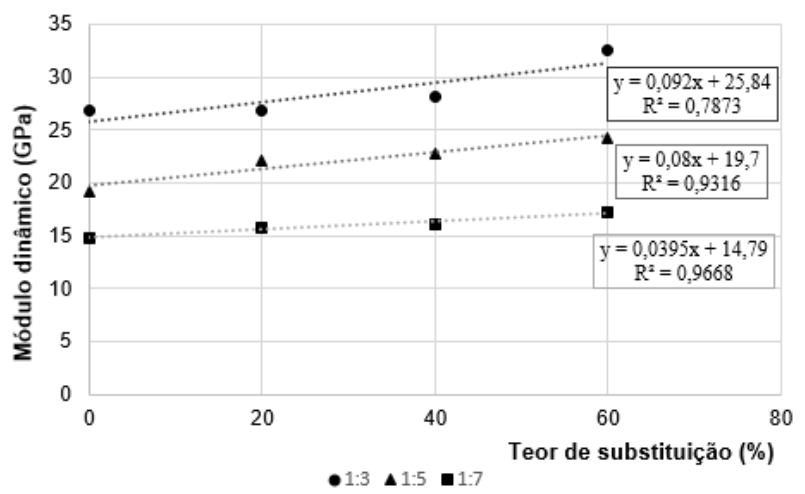

Figura 17: Correlação entre o teor de substituição e o módulo dinâmico das argamassas de cimento Portland.

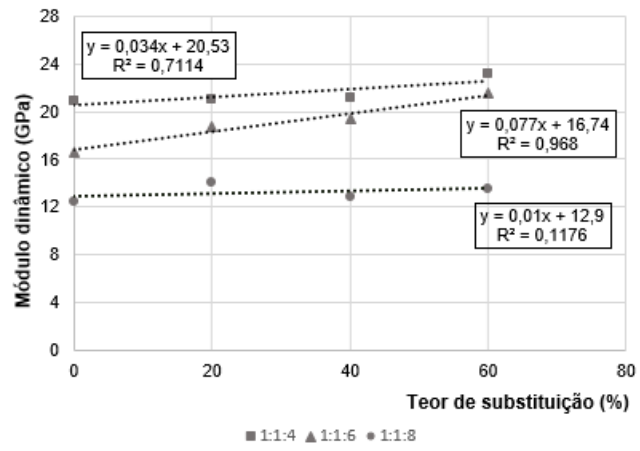

Figura 18: Correlação entre o teor de substituição e o módulo dinâmico das argamassas mistas

Em adição em virtude dos traços mais ricos apresentaram maior módulo de elasticidade dinâmico, foi possível estabelecer a correlação entre o módulo dinâmico e o consumo de cimento $\left(\mathrm{kg} / \mathrm{m}^{3}\right)$ para as argamassas de cimento Portland, e o consumo de cal $\left(\mathrm{kg} / \mathrm{m}^{3}\right)$ para as argamassas mistas, conforme apresentado na Figura 19.
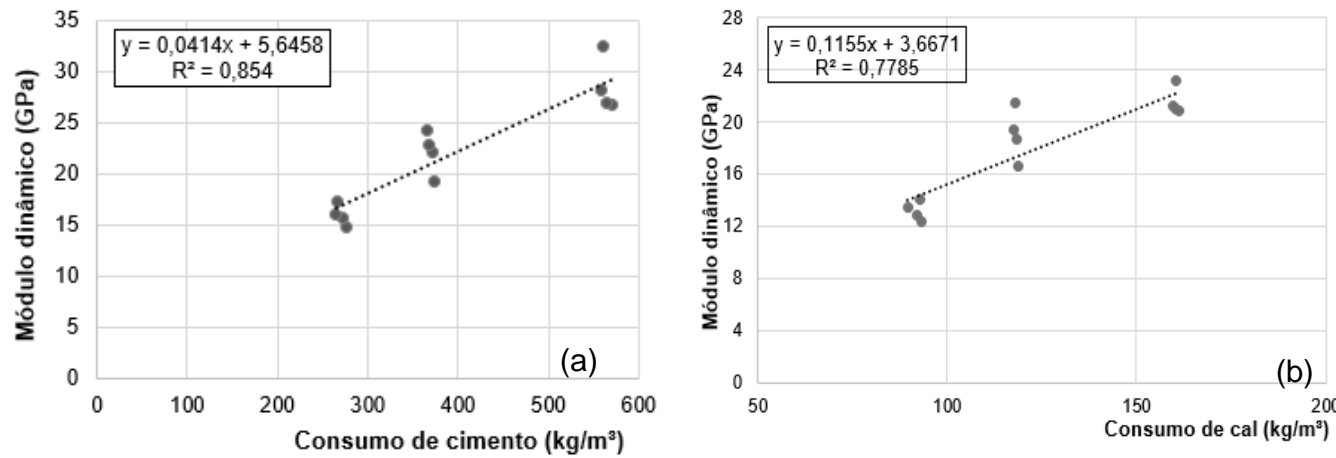

Figura 19: a) Correlação entre o consumo de cimento $\left(\mathrm{kg} / \mathrm{m}^{3}\right)$ e o módulo dinâmico das argamassas de cimento Portland ; b) Correlação entre o consumo de cimento $\left(\mathrm{kg} / \mathrm{m}^{3}\right)$ e o módulo dinâmico das argamassas mistas.

\section{CONCLUSÕES}

Como todos os materiais constituintes das argamassas são os mesmos, as diferenças no comportamento tanto no estado fresco quando no estado endurecido estão relacionadas ao teor de escória utilizada como substituição da areia.

Inicialmente, na definição da quantidade de água a ser utilizada, pode-se verificar que as argamassas com escória de aciaria demandam um maior fator a/c para o mesmo espalhamento. Fator que pode influenciar no aumento da porosidade das argamassas refletindo, também, no aumento da VPU, porém tal propriedade não sofreu uma alteração significativa.

Quanto a resistência mecânica, apesar de haver um aumento da resistência à compressão e da resistên- 
cia à tração na flexão, a análise de variância constatou que o teor de substituição não influencia na resistência das argamassas. Destaca-se que todas as argamassas enquadram nas classes R6 (resistência à compressão > 3,5 MPa) e P6 (resistência à tração na flexão > 8,0 MPa), conforme NBR 13281:2005 [51].

As argamassas com escória de aciaria BSSF apresentaram maiores valores de módulo de elasticidade dinâmico, o que se deve possivelmente pela estrutura mais densa dos grãos de escória se comparado com os dá areia natural. Tal aumento pode propiciar a redução da vida útil dos revestimentos, ao passo que argamassas com maiores valores de módulo tendem a apresentar menor capacidade de absorver deformações, e consequentemente apresentar uma maior quantidade de fissuras.

\section{AGRADECIMENTOS}

Os autores agradecem a CAPES e ao PEC UFC.

\section{BIBLIOGRAFIA}

[1] JANUZZI, R. V. "Modelagem do comportamento mecânico de blocos e prismas produzidos com escória de aciaria elétrica para alvenaria estrutural", Dissertação de M.Sc, PEC/UFOP, Ouro Preto, MG, Brail, 2014.

[2] WORDSTEEL ASSOCIATION. World steel in figures 2018. In: Belgium. ISBN: 978-2-930069-89-0.

Disponível em : https://www.worldsteel.org/en/dam/jcr:f9359dff-9546-4d6b-bed0-

996201185b12/World+Steel+in+Figures+2018.pdf. Acesso em 10 de janeiro, 2019.

[3] BRASIL, Departamento Nacional de produção mineral - Sumário Mineral. Brasília: DNPM, 2016.135 p. ISSN 0101 2053, http://www.dnpm.gov.br/dnpm/publicacoes/serie-estatisticas-e-economia-mineral/sumariomineral/sumario-mineral-brasileiro-2015, acessado em 10 de janeiro, 2019

[4] IABr. Relatório de Sustentabilidade, http://www.acobrasil.org.br/sustentabilidade/. Acessado em 18 de janeiro de 2018

[5] ROJAS, M. F. ROJAS, M. I. S. "Chemical assessment of the electric arc furnace slag as construction material: Expansive compounds", Cement and Concrete Research, v. 34 p. 1881-1888, out. 2004.

[6] METWALLY, K.A., FARIED, A.S., TAWFIK, T.A. "Significance of blast furnace as coarse aggregate in concrete", Life Science Journal, v. 14, n. 9, pp 1-6, 2017

[7] LUXÁN, M.P., SOTOLONGO, R., DORREGO, F., et al., "Characteristics of the slags produced in the fusion of scrap steel by electric arc furnace", Cement and Concrete Research, v.30, pp. 517-519, Apr., 2000

[8] TOSSAVAINEN, M., ENGSTROM, F., YANG,Q., et al., "Characteristics of steel slag under different cooling conditions", Waste Management, v. 27, pp. 1335-1344, 2007.

[9] WANG, G. "Determination of the expansion force of coarse steel slag aggregate", Construction and Building Materials, v. 24, pp. 1961-1966, out 2010.

[10] ABU-EISHAH S. I, EL-DIEB A. S, BEDIR M. S., "Performance of concrete mixtures made with electric arc furnace (EAF) steel slag aggregate produced in the Arabian Gulf region", Construction and Building Materials, v.34. pp. 249-256, Sep. 2012.

[11] AHMEDZADE,P., SENGOZ, B. "Evaluation of steel slag coarse aggregate in hot mix asphalt concrete", Journal of Hazardous Materials, v.165, pp. 300-305, junho 2009.

[12] XUE, Y., WU, S., HOU, H., et al., "Experimental investigation of basic oxygen furnace slag used as aggregate in asphalt mixture", Journal of Hazardous Materials, v.138, pp 261-268, novembro 2006.

[13] TAO, G., XIAO, Y., YANG, L., et al., "Characteristics of steel slag filler and its influence on rheological properties of asphalt mortar", Construction and building materials, v. 201, pp. 439-446. 2019

[14] TEO, P. T., SEMAN, A. A., BASU, P., et al., "Characterization of EAF steel slag waste: The potential green resource for ceramic Tile production”, Procedia Chemistry, v. 19, pp. 842-846, 2016.

[15] BADLEE, H., MAGHSOUDIPOUR, A., DEHKORDI, B. R. "Use of Iranian steel slag for production of ceramic floor tiles", Advances in Applied Ceramics, v. 107, n.2, pp. 111-115, julho 2013.

[16] BAI, T., SONG, Z.G., WU, Y. G., et al., "Influence of steel slag on the mechanical properties and curing time ofmetakaolin geopolymer", Ceramics International, v. 44, pp. 15706-15713, setembro 2018.

[17] WANG, W., SARDANS, J., LAI, D. Y. F., et al., "Effects of steel slag application on grenhouse gas emissions and crop yield over multiple growing seasons in a subtropical paddy field in China", Field Crops Research., v. 171, pp. 146-156, fevereiro, 2015.

[18] GAO, X., OKUBO, M., MARUOKA, N., et al., "Production and utilisation of iron and steelmaking slag 
in Japan and the application of steelmaking slag for the recovery of paddy fields damaged by Tsunami", Mineral Processing and Extractive Metallurgy, v.124, pp. 116-124, setembro 2015.

[19] HE, H., TAM, N. F. Y., YAO, A., et al., "Growth and Cd uptake by rice ( Oryza sativa) in acidic and Cd - contaminated paddy soils amended with steel slag", Chemosphere. v. 189, pp. 247-254, setembro 2017.

[20] QIANG, W., PEIYU, Y., JIANWEI, Y., et al., "Influence of steel slag on mechanical properties and durability of concrete", Construction and Building Materials, v. 47, pp 1414-1420, outubro 2013.

[21] QASRAWI, H. "The use of steel slag aggregate to enhance the mechanical properties of recycled aggregate concrete and retain the environment", Construction and Building Materials, v. 54, pp. 298-304, março 2014.

[22] RONDI, L. R., SORLINI, S., COMINOLI, L., et al., "Concrete woth EAF steel slag as aggregate: A comprehensive technical and environmental characterization", Composites Part B, v.90, pp. 195-202, abril 2016.

[23] MONOSI, S., RUELLO, M. L., SANI, D. "Electric arc furnace slag as natural aggregate replacement in concrete production", Cement and concrete composites, v. 66, pp 66-72, junho 2016.

[24] ADEGOLOYE,G., BEAUCOUR, A.L., ORTOLA,S., et al., "Mineralogical composition of EAF slag and stabilised AOD slag aggregates and dimensional stability of slag aggregate concretes", Construction and Building Materials, v.115, pp 171-178, julho 2016.

[25] CARASEK, H. “Argamassas”, In: Isaia, G.C. (ed.). Materiais de Construção Civil e Princípios de Ciência e Engenharia de Materiais, São Paulo, IBRACON, pp. 892-944, 2010.

[26] MANSO, J. M., RODRIGUEZ, A., ARAGÓN, A., et al., "The durability of masonry mortars made with ladle furnace slag", Construction and Building Materials, v.25, pp 3508-3519, Agosto, 2011.

[27] LIU, J., GUO, D., ZHU, J., et al., "Status and development of the comprehensive utilization of steel slag at Baosteel”, Baosteel Technical Research, v. 5, n 2, 2011.

[28] SOUZA, T. V. P. Caracterização de escória de conversor a oxigênio obtida no processo BSSF antes e após tratamento hidrometalúrgico. Dissertação (Mestrado em Ciência de Materiais) - Centro de Tecnologia, Universidade Federal do Ceará, Fortaleza, 2016.

[29] ABNT - ASSOCIAÇÃO BRASILEIRA DE NORMAS TÉCNICAS. NBR NM 248: Agregados - Determinação da composição granulométrica. Rio de Janeiro, 2003.

[30] ABNT - ASSOCIAÇÃO BRASILEIRA DE NORMAS TÉCNICAS. NBR 7211. Agregados para concreto - Especificação, Rio de Janeiro, 2009.

[31] CARASEK, H., ARAÚJO, R. C., CASCUDO, O., et al., "Parâmetros da areia que influenciam a consistência e a densidade de massadas argamassas de revestimento", Revista Matéria, v.21, n.3, pp. 714-732, jul. 2016.

[32] CARASEK, H.; GIRARDI, A. C.C.; ARAÚJO, R. C.; ANGELIM, R.; CASCUDO, O. "Estudo e avaliação de agregados reciclados de resíduo de construção e demolição para argamassas de assentamento e de revestimento", Cerâmica, v. 64, n. 370, pp. 288-300, Apr. 2018.

[33] ASSOCIAÇÃO BRASILEIRA DE NORMAS TÉCNICAS. NBR NM 45: Agregados - Determinação da massa unitária e do volume de vazios. Rio de Janeiro, 2006.

[34] ASSOCIAÇÃO BRASILEIRA DE NORMAS TÉCNICAS. NBR NM 52: Agregado miúdo - Determinação da massa específica e massa específica aparente. Rio de Janeiro, 2009.

[35] ASSOCIAÇÃO BRASILEIRA DE NORMAS TÉCNICAS. NBR NM 46: Agregados - Determinação do material fino que passa através da peneira $75 \mu \mathrm{m}$, por lavagem. Rio de Janeiro, 2003.

[36] ASSOCIAÇÃO BRASILEIRA DE NORMAS TÉCNICAS. NBR 6467. Agre gados - Determinação do inchamento de agregado miúdo - Método de ensaio, Rio de Janeiro, 2006 (Versão corrigida: 2009).

[37] BESSA, I. S. Avaliação do processamento digital de imagens como ferramenta para caracterização de agregados e misturas asfálticas. Dissertação de M.Sc. Universidade Federal do Ceará. Programa de Pósgraduação em Engenharia de Transportes, 2012.

[38] AL ROUSAN, T. M. (2004) "Characterization of Aggregate Shape Properties Using a Computer Automated System", Tese de D. Sc., Office of Graduate Studies, Texas A\&M University, Texas, USA, 2004.

[39] CAMPOS, S.A, RAFAEL, M. F.C., CABRAL, A. E. B. "Evaluation of steel slag of Companhia Siderúrgica do Pecém replacing fine aggregate on mortars", Procedia Structural Integraty, v. 11, pp. 145-152, 2018. 
[40] ASSOCIAÇÃO BRASILEIRA DE NORMAS TÉCNICAS. NBR 13276: Argamassa para assentamento e revestimento de paredes e tetos - Determinação do índice de consistência. Rio de Janeiro, 2016.

[41] ASSOCIAÇÃO BRASILEIRA DE NORMAS TÉCNICAS. NBR 16541: Argamassa para assentamento e revestimento de paredes e tetos - Preparo da mistura para a realização de ensaios, Rio de Janeiro, 2016.

[42] ASSOCIAÇÃO BRASILEIRA DE NORMAS TÉCNICAS. NBR 13280: Argamassa para assentamento e revestimento de paredes e tetos - Determinação da densidade de massa aparente no estado endurecido. Rio de Janeiro, 2005.

[43] ASSOCIAÇÃO BRASILEIRA DE NORMAS TÉCNICAS. NBR 13279: Argamassa para assentamento e revestimento de paredes e tetos - Determinação da resistência à tração na flexão e à compressão. Rio de Janeiro, 2005.

[44] ASSOCIAÇÃO BRASILEIRA DE NORMAS TÉCNICAS. NBR 15630: Argamassa para assentamento e revestimento de paredes e tetos - Determinação do módulo de elasticidade dinâmico através da propagação de onda ultrassônica. Rio de Janeiro, 2008.

[45] SANTAMARÍA-VICARIO, I., RODRÍGUEZ,A. GONZÁLEZ,S.G., et al., "Durability behavior of steelmaking slag masonry mortars", Materials and design, v. 97, pp. 307-315, maio 2016.

[46] OUDA, A.S., ABDEL-GAWWAD, H.A. "The effect of replacing sand by iron slag on physical, mechanical and radiological properties of cement mortar”, HBRC Journal, v. 13, pp. 255-261, 2017.

[47] OZTURK, M., AKGOL,O., SEVIM, U.K., et al., "Experimental work on mechanical, electromagnetic and microwave shielding effectiveness properties of mortar containing electric arc furnace slag", Construction and Building Materials, v. 165, pp. 58-63, março 2018.

[48] QASRAWI, H. Y., SHALABI, F., ASI, I. "Use of low $\mathrm{CaO}$ unprocessed steel slag in concrete as fine aggregate", Construction and Building Materials, v. 23, pp. 1118-1125, fevereiro 2009.

[49] BRAND, A. S. ROESLER, J. R. "Interfacial transition zone of cement composites with steel furnace slag aggregates", Cement \& Concrete Composites, v. 86, pp. 117-129, 2018.

[50] LACERDA, C., "Traços de argamassa utilizando escória de aciaria elétrica", Tese de M. Sc. / Mestrado Profissional em Materiais/UniFOA, Volta Redonda, RJ, Brasil, 2015.

[51] ASSOCIAÇÃO BRASILEIRA DE NORMAS TÉCNICAS. NBR 13281: Argamassa para assentamento e revestimento de paredes e tetos - Requisitos. Rio de Janeiro, 2005.

[52] SANTAMARÍA-VICARIO, I.. RODRÍGUEZ,A., GONZÁLEZ, S.G., et al., "Design of masonry mortars fabricated concurrently with diferent steel slag aggregates", Construction and Building Materials, v. 95, pp. 197-206, outubro 2015.

[53] HADDAD, L.D., COSTA, C.M., LOPES, P. H. P., et al.,"Análise da influência da granulometria do agregado miúdo nas propriedades mecânicas e de durabilidade das argamassas de revestimento", Ciência \& Engenharia, v. 25, n. 1, pp. 07-16, jan. - jun. 2016.

[54] DO Ó, S. W. "Análise da retenção de água em argamassas de revestimento aditivadas", Dissertação de M.Sc, Universidade de Brasilia, Faculdade de Tecnologia, Brasilia,DF, Brasil, 2004.

[55] LUXAN, M. P., SOTOLONGO, R., DORREGO, F., et al., "Characteristics of the slag produced in the fusion of scrap steel by eletric arc furnace", Cement and Concrete Research, v. 30, pp. 517-519, abril, 2000.

[56] MOTZ, H. GEISELER, J. "Products of steel slag an opportunity to save natural resources", Waste management., v. 21, pp. 285-293, junho 2001.

[57] CARRIJO, P.M., "Análise da influência da massa específica de agregados graúdos provenientes de resíduos de construção e demolição no desempenho mecânico do concreto", Dissertação de M.Sc, Politécnica da Universidade de São Paulo, Departamento de Engenharia de Construção Civil, São Paulo, SP, Brasil, 2005.

[58] NAKAKURA, E. H., CINCOTTO, M. A. "Análise dos requisitos de classificação de argamassas de assentamento e revestimento", In: BT/PCC/359 - Boletim Técnico da Escola Politécnica da USP, Departamento de Engenharia de Construção, São Paulo, 2004.

[59] SILVA, N. G., "Argamassa de Revestimento de Cimento, Cal e Areia Britada de Rocha Calcária”, Dissertação de M.Sc, Universidade Federal do Paraná, Curitiba, PR, Brasil, 2006.

ORCID

Felipe Alves Amancio

Douglas Alexandre Lima
https://orcid.org/0000-0002-1349-683X

https://orcid.org/0000-0003-0671-4920 
Alisson Rodrigues de Oliveira Dias

Esequiel Fernandes Teixeira Mesquisa

Antonio Eduardo Bezerra Cabral https://orcid.org/0000-0002-9892-6834

https://orcid.org/0000-0001-9905-6220

https://orcid.org/0000-0001-6394-1164 